\title{
Lupeol inhibits growth and migration in two human colorectal cancer cell lines by suppression of Wnt- $\beta$-catenin pathway
}

\section{Yihao Wang ${ }^{1,2, *}$ \\ Dan Hongl,* \\ Yuqin Qian ${ }^{3}$ \\ Xuezi Tu' \\ Keke Wang' \\ Xianhong Yang' \\ Sijia Shao' \\ Xinlong Kong' \\ Zhefeng Lou' \\ Longjin Jin'}

'School of Laboratory Medicine and Life Science, Wenzhou Medical University, Zhejiang, People's Republic of China; ${ }^{2}$ School of Ophthalmology and Optometry, Wenzhou Medical University, Zhejiang, People's Republic of China; ${ }^{3}$ School of the first Clinical Medical Sciences, Wenzhou Medica University, Zhejiang, People's Re of China

*These authors contribu equally to this work

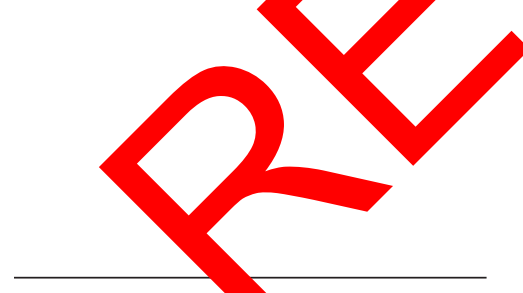

Correspondence: Lorgjin Jin;

Zhefeng Lou

School of Laboratory Medicine and Life Science, Wenzhou Medical University, 270 Xueyuan Road West, Wenzhou, Zhejiang 325035, People's Republic of China

Tel +86 I39 6889 I |43;

+86 I385776 I455

Fax +8657786699388

Email Iswyh1997@I63.com;

Izf@wmu.edu.cn
This article was published in the following Dove Press journal: OncoTargets and Therapy

Background: Lupeol, a triterpene isolated anti-inflammatory function and has been prop as candidate lor anticancer agents. The purpose of this research was to investigat ne effo lupeol on viability, apoptosis, cellcycle distribution, and migration of colo al cancer ce ine nd its molecular mechanism. Methods: Lupeol was assessed for intica r effect usin_, wwo human colorectal cancer cell lines: SW480 and HCT116. These cells were tre 1 with lupeol, and their viability, apoptosis, migration, and cycle distriby on were detected by CK8, flow cytometry, and the transwell method. Quantitative PCR, Vestern blot, $\mathrm{d}$ immunofluorescence were applied to detect the expressions of CTNNB1, T 4, CMYC, CC IDI, CLDN1, and CCNA2.

Results: Lupeol suppressed o viabilit nd migration and induced cellular apoptosis of both cell lines, with in 53 and actreased Bcl2 protein levels $(P<0.05)$. Cell cycles of both lupeol-treated cell es y the $\mathrm{S}$ phase $(P<0.05)$. Quantitative PCR and Western blot an showe Enificantly reduced expressions of CTNNB1, TCF4, and downstream gen of the Int- $\beta$ - $\mathrm{c}$ enin pathway, including the cell-cycle-regulated genes of $c M Y C$ and NDI of . boll linc upon lupeol treatment $(P<0.05)$. mRNA and protein levels of $C L D N 1$ dec in HCTIro cells, plus the expression of $C C N A 2$ mRNA and protein decreased in SW480 1ls $(P<0.05)$. Immunofluorescence analysis confirmed decreased expression of Wnt $-\beta$-cat in signaling.

nclusion: Our findings indicate that lupeol effectively inhibits proliferation and migration anc duces apoptosis and cell-cycle arrest of two colorectal cell lines by inactivation of the Wnt $-\beta$-catenin signaling pathway and downregulation of $C M Y C, C C N D 1, C C N A 2$, and $C L D N 1$, thereby making it a promising anticancer candidate.

Keywords: lupeol, colorectal cancer, Wnt, $\beta$-catenin signaling pathway, proliferation, apoptosis, migration

\section{Introduction}

Colorectal cancer (CRC) is the third-most common type of cancer in the world. ${ }^{1}$ Alkylating cytotoxic agents like oxaliplatin are usually combined with radiotherapy to treat stage II and stage III CRC, which confronts obstacles like multidrug resistance and severe side effects. These therapies ultimately lead to drug intolerance and tumor relapse in CRC patients. ${ }^{2}$ Plants contain a wide range of potential anticancer-drug substances with multifarious functions and targets. In recent years, triterpenes, including lupane, oleanane, and ursane, have shown their potential as anticancer candidates by various methods of administration, such as gavage and subcutaneous and intravenous injection in animal models. ${ }^{3}$ 
Lupeol is a pentacyclic triterpene in the lupane group, widely found in herbal plants like kale, mango, and dandelion, with anti-inflammatory, antioxidation, anti-infective, antihyperglycemia, antiasthma, antiarthritis, cardioprotective, neuroprotective, hepatoprotective, and chemosensitization effects. ${ }^{4,5}$ This evidence supports lupeol possessing varied pharmacological potency with many potential mechanisms and targets. However, its complicated molecular mechanism and whether lupeol might be a promising leading compound to treat $\mathrm{CRC}$ remain unclear.

The high prevalence of CRC calls for therapeutic agents targeting the mechanism of its premalignant lesions and evolution of cancer. An aberrantly activated Wnt- $\beta$-catenin signaling pathway is a common feature involved in $93 \%$ of CRC. Two most frequent gene mutations in carcinogenesis resulting in excessive accumulation of $\beta$-catenin are $A P C$ mutations ( $82 \%$ ) and the activation of $C T N N B 1$ itself $(4.7 \%) .{ }^{6}$ These mutations lead to disruption of $\beta$-catenin degradation in cytoplasm. Excessive $\beta$-catenin translocates to the nucleus to bind with TCF/ LEF transcription factors to form the $\beta$-catenin-TCF complex, which binds to promoter regions of $C C N D 1$ and $C M Y C$, thereby accelerating metabolic activation of the cell cycle in malignant transformation. ${ }^{7}$ GeneCards and Kyoto Encyclopedia of Genes and Genomes signaling pathways both indicate that $C C N A 2$ is located downstream of the Wnt pathway and regulated by $\mathrm{W}$ target gene transcription of cMyc. ${ }^{8}$ Overexpression of $C C N A$ can result in delayed onset of cell division in mamm 2 cells. ${ }^{9}$ CCNA2 may also regulate oncoproteins or tum suppi sors like TP53, contributing to tumorigenesis.

regulated by $\beta$-catenin and TCF4 an ${ }^{\prime}$ ighly eased in $\mathrm{CRC}$, helping promote cellular $\mathrm{n}$ mant trans mation through regulating epithelial-mes achym ransition (EMT). ${ }^{11}$ Therefore, targeting the caso activation o Wnt- $\beta$-catenin signaling transcription is acial fo $\mathrm{CRC}$ therapy. ${ }^{12}$

Here, we explored effe of lupeol on the viability, apoptosis, cell cy and gration CRC cell lines, ie, SW480 (APC deleted $\beta$-cato Mld type) and HCT116 (APC wilk vpe, $\rho$ min mutant). Furthermore, we explored the $\mathrm{n}$ anism of lupeol-mediated suppression in CRC cell lines or Unt- $\beta$-catenin signaling by evaluating expressions of $C T N N \Delta 1, T C F 4$, and Wnt- $\beta$-catenin signaling downstream genes $C M Y C, C C N D 1, C L D N 1$, and CCNA2.

\section{Methods}

\section{Cell culture}

The human CRC cell lines SW480 and HCT116 were obtained from the Cell Bank of Type Culture Collection of the Chinese Academy of Sciences (Shanghai, People's Republic of China). Both cell lines are regularly authenticated on the basis of viability, recovery, growth, morphology, and chemical response, most recently confirmed 3-4 months before use. Both cell lines were cultured in RPMI 1640 medium supplemented with $10 \%$ FBS with $1 \%$ penicillinstreptomycin (CellGro; Corning Incorporated, Corning, NY, USA) in humidified air with $5 \% \mathrm{CO}_{2}$ at $37^{\circ} \mathrm{C}$.

\section{Chemical reagents}

Lupeol was purchased from Sigma-Aldrich Co. (St Louis, MO, USA) and dissolved in dimethyl sulfoxide (DMSO) at a concentration of $2.4 \times 10^{-2} \mathrm{~mol} / \mathrm{L}$ as a stock solution. The solution was diluted to give a final $\mathrm{DM}$ an ancentration of $0.1 \%$ (v:v) and stored at $-80^{\circ} \mathrm{C}$. The ntrol gro contained DMSO at this concentration. Cyc A2 (ab38) d claudin 1 (ab15098) antibodies were archaso from $\mathrm{Ab}$ am (Cambridge, UK). $\beta$-Catenin A0066 and o 01 (AF853) antibodies were bough "om yotime(Haimen, People's Republic of Chin GAPL (sc477?, cMyc (sc40), and $\beta$-actin ( Cruz Biotecmnology (Dallas, TX, USA). TCF4 (2565s), p53 (92 Bcl2 (287 antirabbit IgG (H+L, 4412), and anti ouse $\operatorname{IgG}(\mathrm{H}+\mathrm{L}, 8890)$ antibodies were bought from Cel Signaling To hnology (Danvers, MA, USA). Antirabbit (s 004) and Atimouse (sc2005) IgG-HRP-conjugated ceondary abodies were purchased from Santa Cruz By logy Inc. Trizol reagent was bought from Thermo isher Scientific (Waltham, MA, USA).

\section{Eell-viability assay}

Cell viability was determined using CCK8 (Beyotime, Shanghai, People's Republic of China). Cells $\left(10^{4}\right.$ per well) were seeded into a 96-well plate in $100 \mu \mathrm{L}$ RPMI 1640 supplemented with $10 \% \mathrm{FBS}$ and allowed to adhere overnight. After treatment with lupeol at various concentrations for 24 and 48 hours, $10 \mu \mathrm{L}$ CCK8 solution was added to each well of the plate. Plates were incubated at $37^{\circ} \mathrm{C}$ for 1 hour, after which absorbance at $450 \mathrm{~nm}$ was measured using a microplate reader (BioTek, Winooski, VT, USA). All experiments were performed in triplicate and repeated at least three times.

\section{Cell-apoptosis assay}

Cells $\left(2 \times 10^{5}\right)$ were stained with fluorescein isothiocyanateconjugated anti-annexin $\mathrm{V}$ antibody, which was labeled in combination with propidium iodide (PI) according to the manufacturer's protocol (KeyGen Biotech, Nanjing, People's Republic of China), then analyzed by fluorescence-activated cell sorting (BD, Franklin Lakes, NJ, USA). The cell-death percentage corresponded to annexin $\mathrm{V}^{+}-\mathrm{PI}^{+}$cells. The apoptotic cell-death percentage was represented by annexin $\mathrm{V}^{+}-\mathrm{PI}^{-}$-stained cells. 


\section{Cell-cycle analysis}

Cells $\left(2 \times 10^{5}\right)$ were cultured in each well of six-well plates till $60 \%$ confluent with normal culture medium. Cells were synchronized by replacing the medium containing $0.1 \%$ FBS for 12 hours to arrest them in the $\mathrm{G}_{0}$ phase of the cell cycle, after which they were treated with or without lupeol in RPMI 1640 complete media for 24 hours. Cells were trypsinized thereafter, washed twice with cold PBS, and centrifuged at $1,500 \mathrm{rpm}$. For cell-cycle analysis, cells were fixed in prechilled $70 \%$ ethanol overnight at $4{ }^{\circ} \mathrm{C}$. Cells were centrifuged at 1,500 rpm for 5 minutes, pellets washed twice with cold PBS, suspended in $500 \mu \mathrm{L}$ PBS, and incubated with $5 \mu \mathrm{L}$ RNase (Takara, Kusatsu, Japan) at $37^{\circ} \mathrm{C}$ for 30 minutes. Cells were chilled over ice for 10 minutes and stained with PI staining solution (PI $50 \mathrm{mg} / \mathrm{mL}$, RNase A $10 \mathrm{mg} / \mathrm{mL}$, and $0.1 \%$ Triton X-100; Sigma-Aldrich Co.) for 1 hour and analyzed by Flow Jo version 10 flow cytometry.

\section{Cell-migration assay}

In vitro cell migration was determined following the manufacturer's instructions. Cells $\left(5 \times 10^{4}\right)$ were seeded in each chamber and left for 24 hours. The stoppers used to create the migration zone were removed after 24 hours, and cells washed with PBS twice to remove any unattached

Fresh RPMI 1640 complete medium $(100 \mu \mathrm{L})$ with lup l or DMSO was added to each well. Cells were al into the migration zone. After incubation the the assay for 48 hours, cells on both the ins and 9 seeded plate were fixed with $4 \%$ malih on transferred to $100 \%$ methanol, and finally ned with ch tal violet at room temperature in the dar They re washed again, then noncrossing cells were aped off with otton swab (PBSwetted). Cells were aorescently stained with CellTracker green (Thermo Fis Sci afic). Fluorescent signals were measured usi- mic ate rea (Synergy HT; BioTek) with 492 exci tion an $\mathrm{nm}$ emission filters.

Revers anscripcion and real-time polymera chain reaction

In this reaction, $2 \mu \mathrm{g}$ total RNA was reverse-transcribed with random primers and SuperScript IV reverse transcriptase according to the user's manual (Thermo Fisher Scientific). The reaction was performed with incubation at $42^{\circ} \mathrm{C}$ for 1 hour, and the enzymes were subsequently inactivated by incubation at $85^{\circ} \mathrm{C}$ for 5 minutes. cDNA was used for realtime PCR analysis with gene-specific primers, and gene expression was detected using a Fast SYBR green master mix (Thermo Fisher Scientific). RNA expression was normalized to that of GAPDH $\left(\Delta \mathrm{C}_{t}=\operatorname{target}\right.$ RNA $\left.\mathrm{C}_{\mathrm{t}}-\mathrm{GAPDH} \mathrm{C}_{\mathrm{t}}\right)$.
Individual primers used in this study were: $C T N N B 1-\mathrm{F}$ : 5'-CATCTACACAGTTTGATGCTGCT-3', R: 5'-GCA GTTTTGTCAGTTCAGGGA-3'; TCF4-F: 5'-GGCTATGC AGGAATGTTGGG-3'，R： 5'-GTTCATGTGGA TGCAGGCTAC-3'; MYC-F: 5'-GTCAAGAGGCGAACA CACAAC-3', R: 5'-TTGGACGGACAGGATGTATGC-3'; CCND1-F: 5'-GCTGCGAAGTGGAAACCATC-3', R: 5'-CCTCCTTCTGCACACATTTGAA-3'; CCNA2-F: 5'-GGATGGTAGTTTTGAGTCACCAC-3', R: 5'-CAC GAGGATAGCTCTCATACTGT-3'; CLDN1-F: 5'-AGC ACCGGGCAGATACAGT-3', -GCCAATTACC ATCAAGGCTCG-3'; and $A P D H-1$ 5'-GGAGCG AGATCCCTCCAAAAT-3', 5'-GGCT TTGTCATA CTTCTCATGG-3'.

\section{Western blo}

Briefly, CRC ells wo washer Aree times after lupeol treatment hours in $3 \mathrm{~S}$ and lysed in lysis buffer containng $20 \mathrm{~m}$ Tris $(\mathrm{pH} 7.5), 150 \mathrm{mM} \mathrm{NaCl}$, and $1 \%$ Tr -100 (Bey ime) supplemented with a proteasethibitor cocktail and phosphatase inhibitor cocktail (MCE) or 30 minu on ice. Homogenates were centrifuged at $000 \mathrm{rpm} / 10$ minutes, and extracted protein concentrations nneasured using BCA assay (23227; Thermo Fisher

- ntific) and determined by Bio-Rad protein assay. Protein lysates $(\sim 40 \mu \mathrm{g})$ were electrophoresed in SDS-PAGE gels and transferred onto polyvinylidene difluoride membranes (ISEQ00010; EMD Millipore, Billerica, MA, USA) by electroblotting. The membranes were blocked with Tris-buffered saline with Tween 20 (TBST) containing 5\% dried milk-BSA for 1 hour at room temperature, followed by incubation with primary antibody for 16 hours. Antibodies of $\beta$-catenin (1:8,000, rabbit), TCF4 (1:400, rabbit), cMyc (1:400, mouse), cyclin D1(1:147, mouse), $\beta$-actin (1:1,000, mouse), cyclin A2 (1:200, mouse), claudin 1 (1:200, rabbit), p53 (1:1,000, rabbit), Bcl2 (1:1,000, rabbit), and GAPDH (1:800, mouse) were incubated. Membranes were washed three times with TBST. Then, membranes were incubated with antirabbit (sc2004) or antimouse (sc2005) IgG-HRP-conjugated secondary antibodies $(1: 10,000)$ for 1 hour. After three washes with TBST (50 mM Tris- $\mathrm{HCl} \mathrm{pH} 7.6,150 \mathrm{mM} \mathrm{NaCl}, 0.1 \%$ Tween 20), immunoreactive bands were detected using a WesternBright enhanced chemiluminescence (RPN2135; GE Healthcare UK Ltd., Little Chalfont, UK). GAPDH or $\beta$-actin was used as an internal loading control.

\section{Immunofluorescence}

Cells were seeded on aseptic $1 \mathrm{~cm}$-diameter disks in a 24-well plate at a density of $2 \times 10^{4}$ cells/disk for 4 days. Samples were 
washed with PBS and fixed in 4\% paraformaldehyde for 15 minutes at room temperature. Cells were washed with PBS three times and blocked with PBS containing 5\% BSA for 1 hour. After being blocked with BSA, samples were incubated with primary antibody $\beta$-catenin (1:200, rabbit; Beyotime), TCF4 (1:50, rabbit; Cell Signaling Technology), cMyc (1:50, mouse; Santa Cruz Biotechnology), cyclin D1 (1:20, mouse; Beyotime), claudin 1 (1:80, rabbit; Abcam), and cyclin A2 (1:80, mouse; Abcam) overnight at $4^{\circ} \mathrm{C}$. On the following day, samples were washed with PBS three times and incubated with goat antirabbit antibody (1:500) or goat antimouse antibody (1:500), which were diluted in a blocking solution for 1 hour at room temperature. Samples were further counterstained with DAPI (1:500; Boster, Pleasanton, CA, USA) and phalloidin (1:100; Beyotime). Inverted fluorescence microscopy (Eclipse Ti; Nikon Corporation, Tokyo, Japan) was used to capture fluorescent images.

\section{Statistical analysis}

Results were statistically analyzed using Student's $t$-test with SPSS 22.0, which were analyzed using GraphPad Prism version 6.0. All experiments were independently repeated at least three times. $P<0.05$ was considered statistically significant. All data are represented as mean $\pm \mathrm{SD}$.

\section{Results}

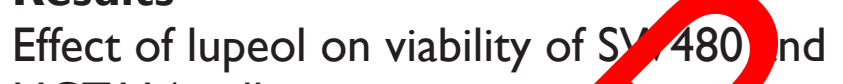
HCTI 16 cells

We investigated the effect of lupeol $\sigma-120 \mu$ rreatment on the viability of an APC-defici line (SW and $\beta$-catenin-mutated cell line (HCT 116) by $\mathrm{C}$ assay. The viability of both cell types trea with lupeol wa ecreased in a dose-dependent manne 24 and 8 hours' lupeol treatment

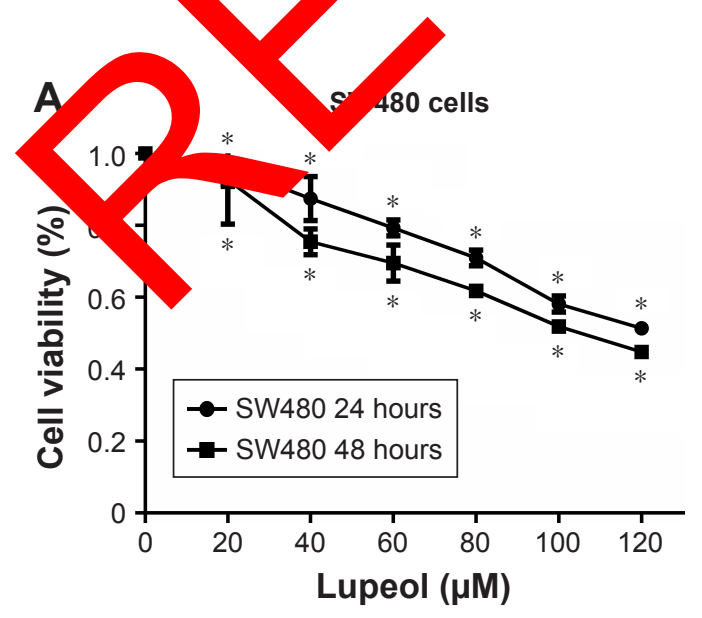

(Figure 1A and B). The $\mathrm{IC}_{50}$ of lupeol treatment at 24 hours of SW480 and HCT116 cells was 106.3 and $62.0 \mu \mathrm{M}$, respectively. The $\mathrm{IC}_{50}$ at 48 hours of SW480 and HCT116 cells was 90.2 and $53.3 \mu \mathrm{M}$, respectively. Based on cell-viability results, we selected various concentrations of lupeol $(0,40,80$, and $120 \mu \mathrm{M})$ for SW480 cells and HCT116 cells (0, 20, 40, and 80 $\mu \mathrm{M}$ ) with 24 hours' treatment for subsequent studies.

\section{Effect of lupeol on apoptosis of SW480 and HCTI 16 cells}

In the cellular apoptosis study, botb cillin vere treated with lupeol or DMSO and assess by flow cyt getry with annexin V-PI double stainin Resw showed at lupeol induced apoptosis in SW 3 and $\mathrm{HCT}, \mathrm{ce}$ in a dosedependent manner $(P<05 ; \mathrm{Fi}$ are $2 \mathrm{~A}-\mathrm{D}$. The p53-wild type HCT116 cell cxer gher ap tosis induction to lupeol exposur an p53-mu a 480 cells. To explore the molecuk mec ism of lup ol in CRC-cell apoptosis, we detected the $\mathrm{Bcl} 2$ d p53 protein levels assessed by Wes $n$ blot (Figure 2E and F). The p53 protein level was inc ased in lup -treated groups. Conversely, Bcl2 level was hibited by high lupeol concentration (Figure $2 \mathrm{G}$ and $\mathrm{H}$.r. $\mathrm{ts}$ indicated that lupeol promoted apoptosis hit cells via the p53 pathway.

\section{Effect of lupeol on cell cycle in SW480 and HCTII 6 cells}

Next, we considered the possibility that growth inhibition of CRC cells may involve an arrest of cells at specific check points in the cell cycle followed by apoptosis. Therefore, we assessed the effect of lupeol on cell-cycle perturbation (Figure 3A and B). Lupeol treatment significantly increased

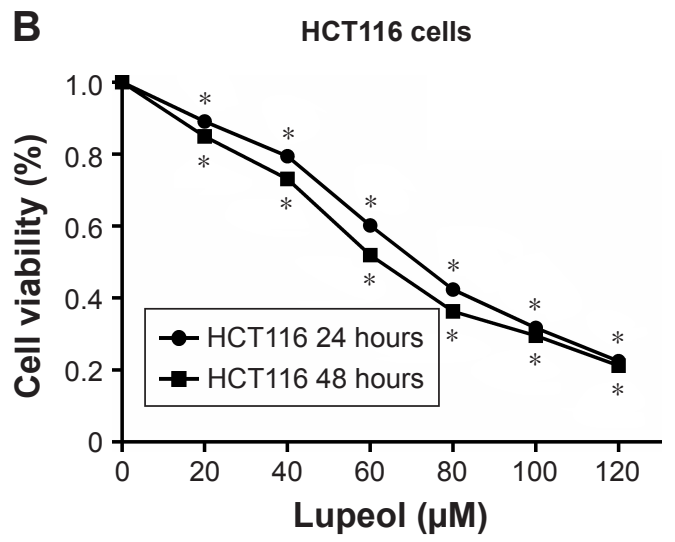

Figure I Effect of lupeol on viability of SW480 and HCTII6 cells assessed by CCK8 assay.

Notes: (A) SW480 cells and (B) HCTII 6 cells were treated with lupeol (0-120 4 M) for 24 and 48 hours and cell viability determined by CCK8 assay. Points: mean of three separate experiments wherein each treatment was repeated in eight wells; mean \pm SD. Asterisks indicate significant differences between the control (dimethyl sulfoxide) and lupeol-treatment groups $(* P<0.05)$. 
A
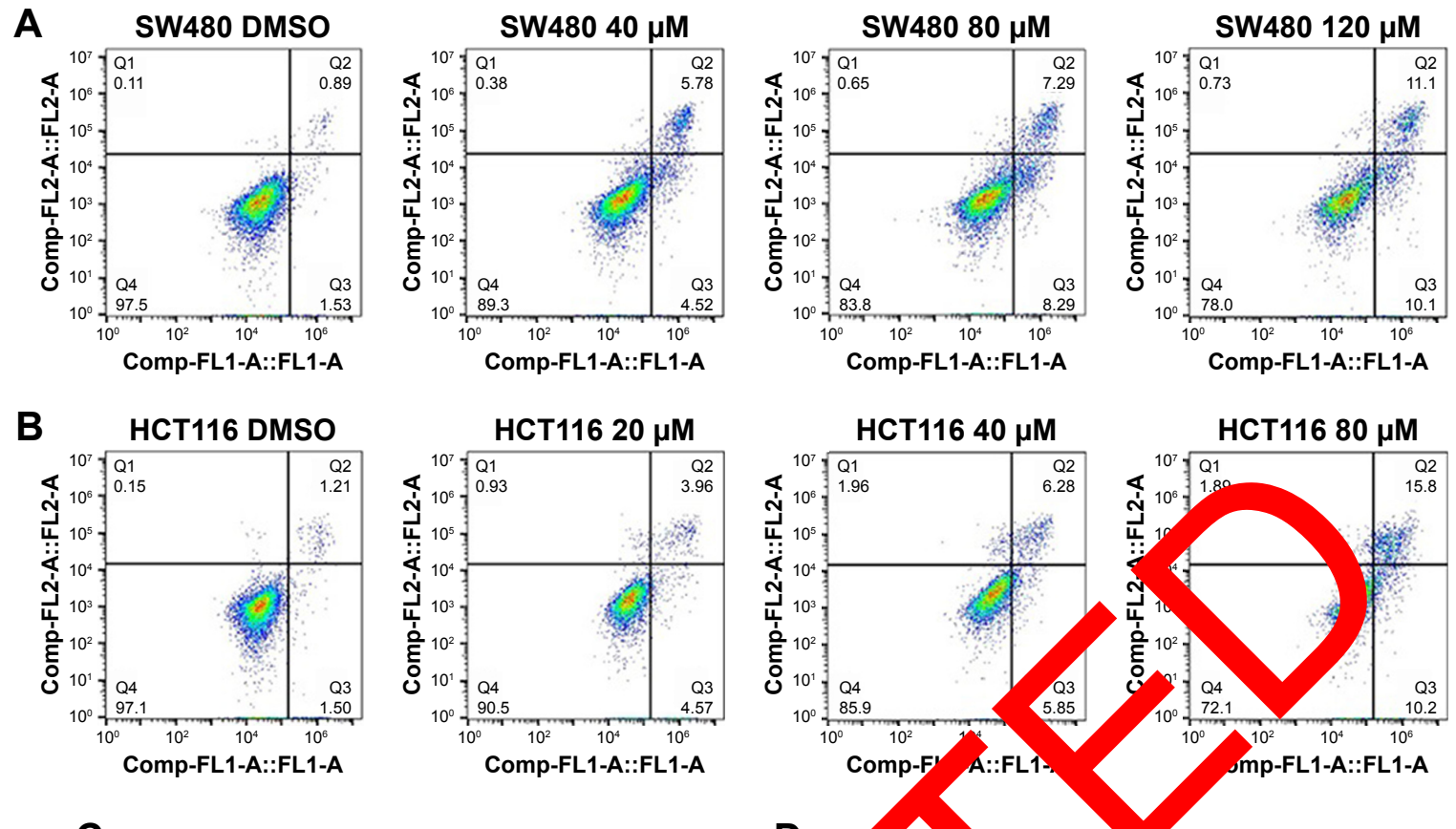

C

SW480 cells

D

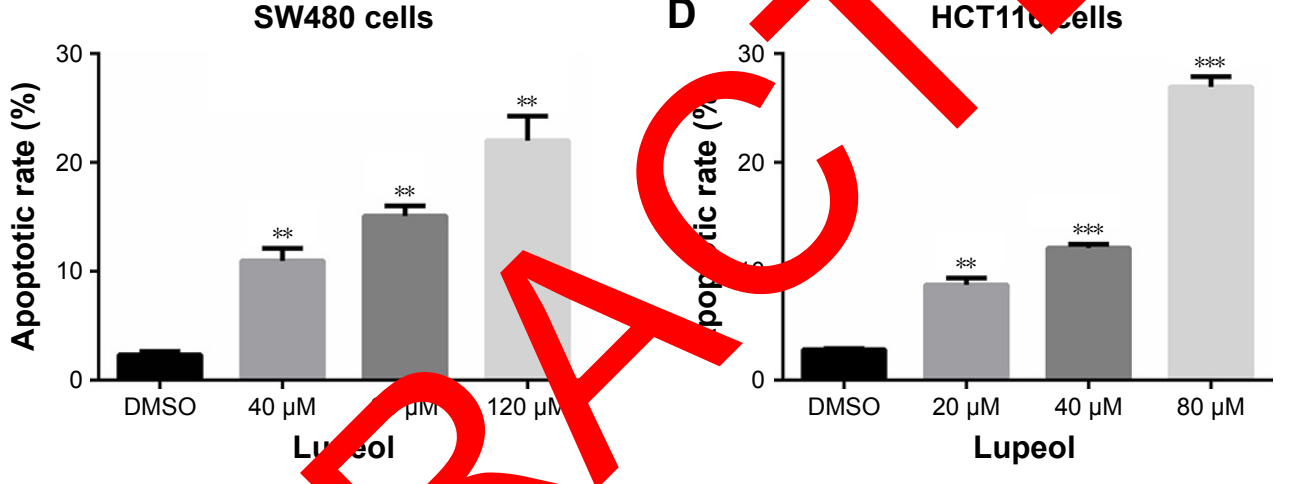

E

$80 \mu \mathrm{M}, 120 \mu \mathrm{M}$

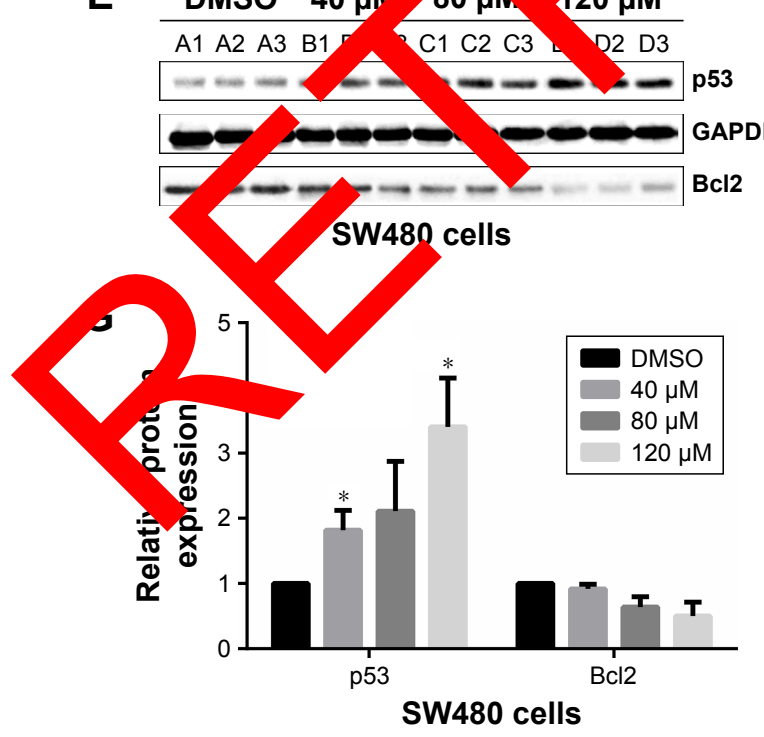

$\mathbf{F}$

DMSO $\quad 20 \mu \mathrm{M} \quad 40 \mu \mathrm{M} \quad 80 \mu \mathrm{M}$

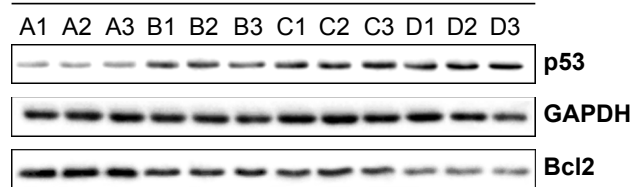

HCT116 cells

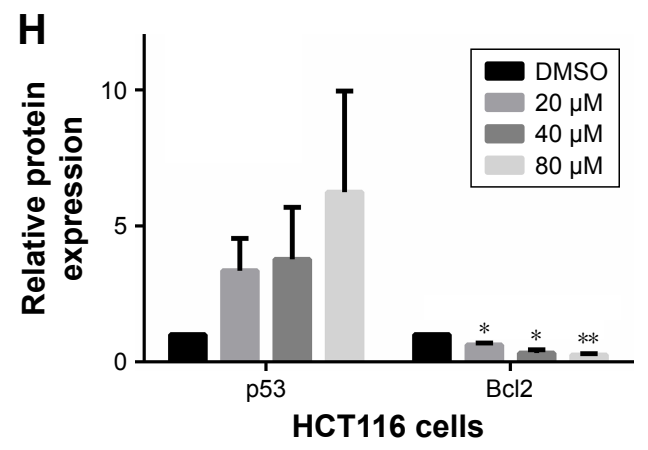

Figure 2 Effect of lupeol on cell apoptosis and protein levels of p53 and Bcl2 in SW480 and HCTII 6 cells assessed by flow cytometry.

Notes: (A) SW480 cells were treated with various concentrations of lupeol $(0,40,80$, and I20 $\mu$ M) for 24 hours. (B) HCTII6 cells were treated with lupeol (0, 20, 40 , and $80 \mu \mathrm{M}$ ) for 24 hours. Apoptotic cells were labeled with annexin V-propidium iodide. The percentages of total apoptotic (C) SW480 cells and (D) HCTII6 cells after 24 hours of lupeol treatment were significantly higher compared with control groups. (E) Percentages of total cellular apoptosis in Western blot analysis of Bcl2 and p53 protein levels in different groups in SW480 cells. (F) Western blot analysis of $\mathrm{Bcl} 2$ and p53 protein levels in different groups in HCTII6 cells. (G) Quantitative protein levels of $\mathrm{Bcl} 2$ and $\mathrm{p} 53$ in SW480 cells. (H) Quantitative protein levels of $\mathrm{Bcl} 2$ and $\mathrm{p} 53$ in HCTII 6 cells. $* \mathrm{P}<0.05 ; * * \mathrm{P}<0.0 \mathrm{I} ; * * * \mathrm{P}<0.00 \mathrm{I}$.

Abbreviation: DMSO, dimethyl sulfoxide. 

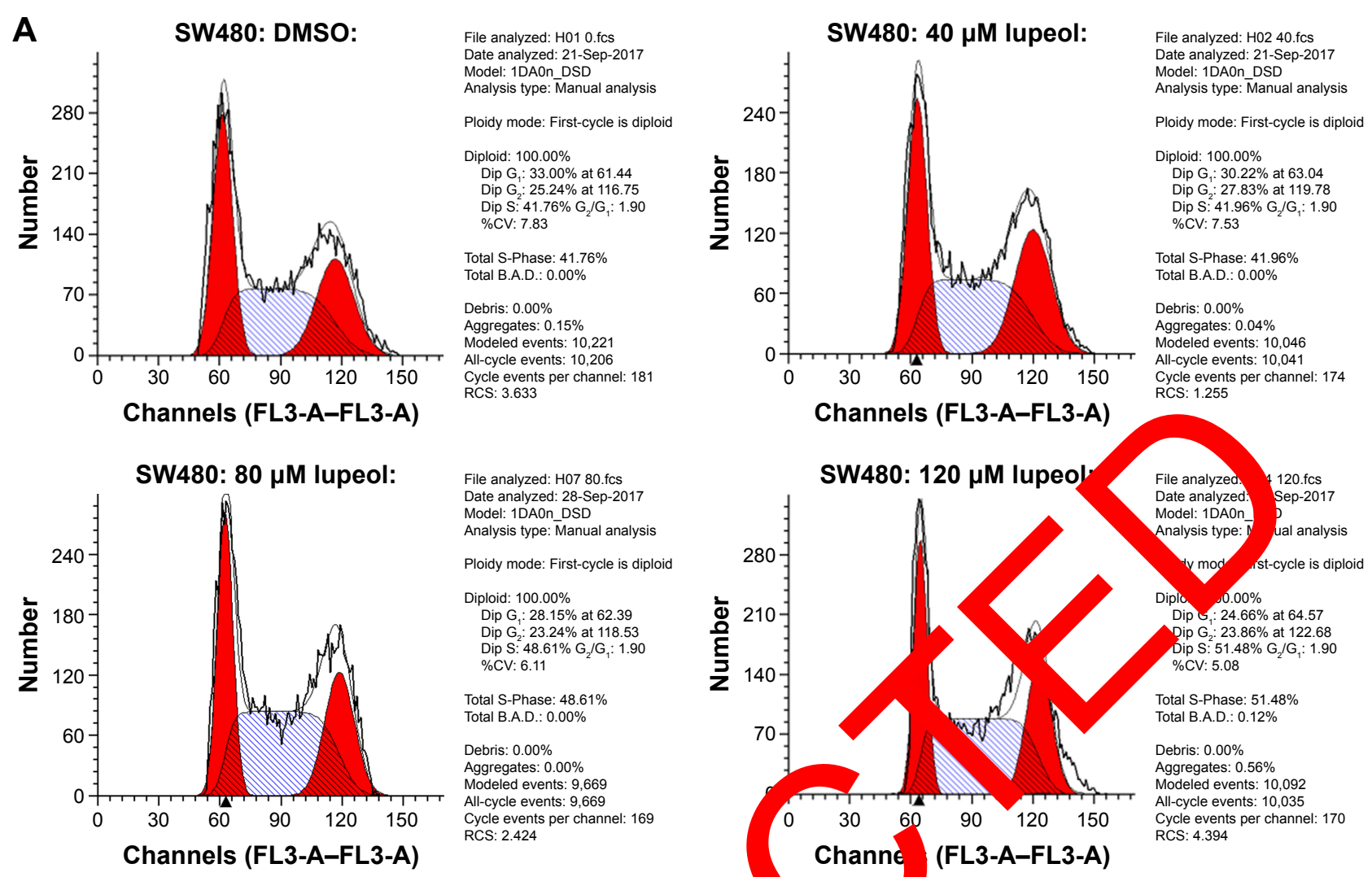

File analyzed: $\mathrm{H} 07$ 80.fCs Date analyzed: 28-Sep-2017 Model: 1 DAOn_DSD
Analysis type: Manual analysis Ploidy mode: First-cycle is diploid Diploid: $100.00 \%$

Dip $G_{1}: 28.15 \%$ at 62.39 Dip S: $48.61 \% \mathrm{G}_{2} / \mathrm{G}_{1}: 1.90$ IPV: $6.11 \% G_{2} / G_{1}: 1.90$

Total S-Phase: $48.61 \%$ Total B.A.D. : $0.00 \%$

Debris: $0.00 \%$ Aggregates: $0.00 \%$ Modeled events: 9,669 All-cycle events: 9,669 Cycle events per channel: 169 RCS: 2.424

B

HCT116: DMSO:

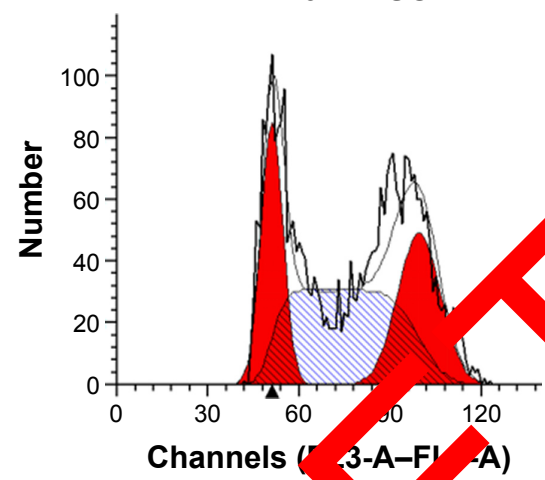

File analyzed: G01 HCT80. Date analyzed: 12-Sep-2017 Model: $1 \mathrm{DAOn}$-DSD
Analysis type: manual analysis

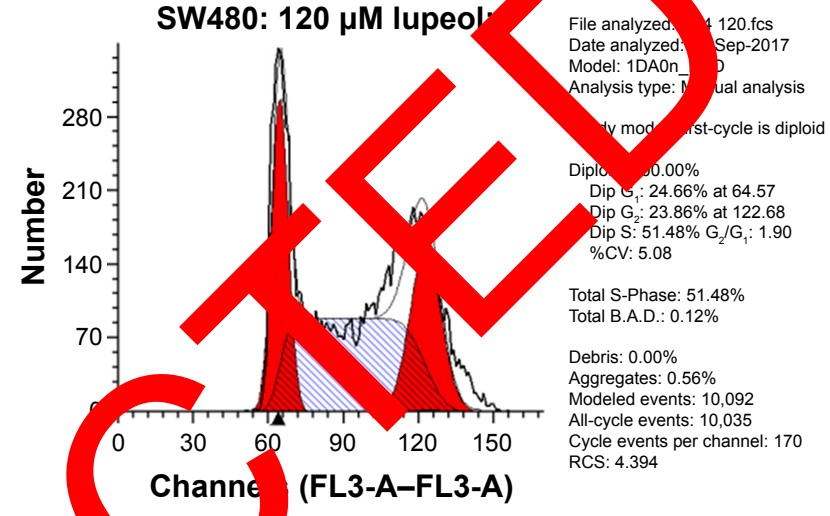

File analyzed, 4 120.fcs Date analyzed. Sep-2017 Analysis type: $\overline{\bar{N}}$ ual analysis

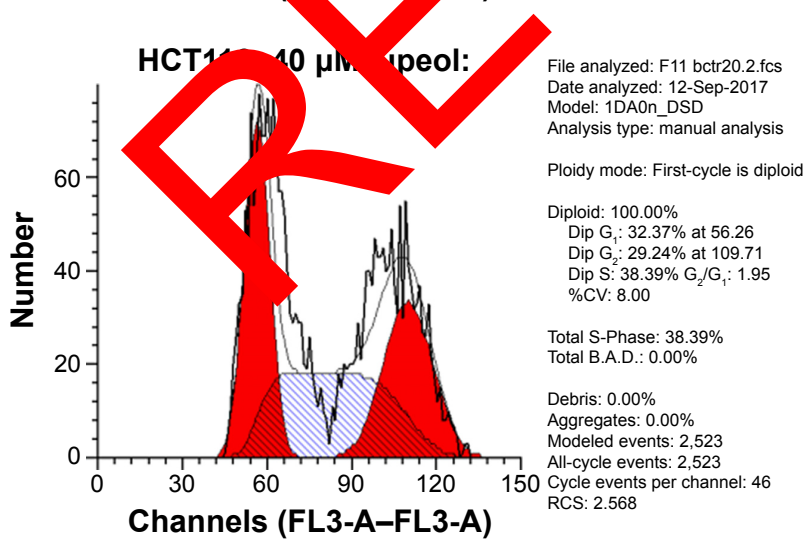

16: $20 \mu \mathrm{M}$ lupeol:

File analyzed: F12 HCT40.2 fcs Date analyzed: 12-Sep-2017 Model: 1DAOn_DSD

manual analysis

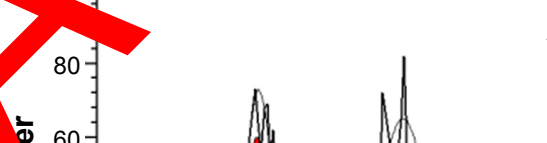

Ploidy mode: first cycle is diploid

Diploid: $100.00 \%$

Dip $G_{1}: 21.79 \%$ at 52.48 Dip $\mathrm{G}_{2}: 36.51 \%$ at 102.33

Total S-Phase: $41.70 \%$ Total B.A.D.: $0.00 \%$

Debris: $0.00 \%$ Aggregates: $0.00 \%$ Modeled events: 2,905

All-cycle events: 2,905 Cycle events per channel: 57 regates: $0.19 \%$ iv events: 3,123 Cycle ts per channel: 63 RCS: 2.3 per channel: 63
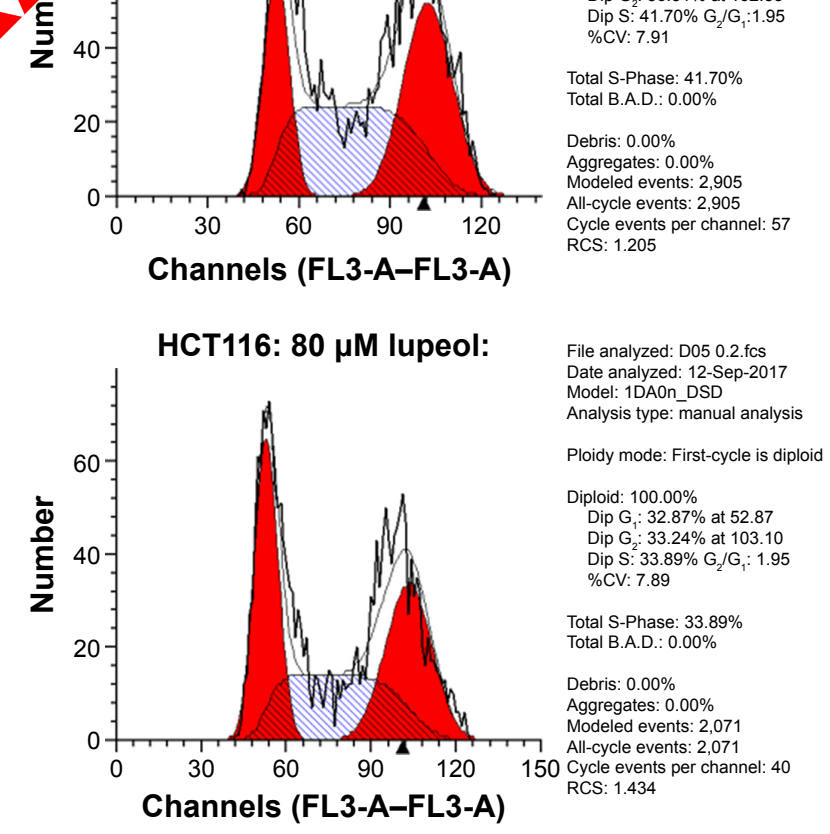

$\square$ Debris $\square$ Aggregates $\square$ Dip G1 $\square$ Dip G2 $₫$ Dip S

Figure 3 (Continued) 
C

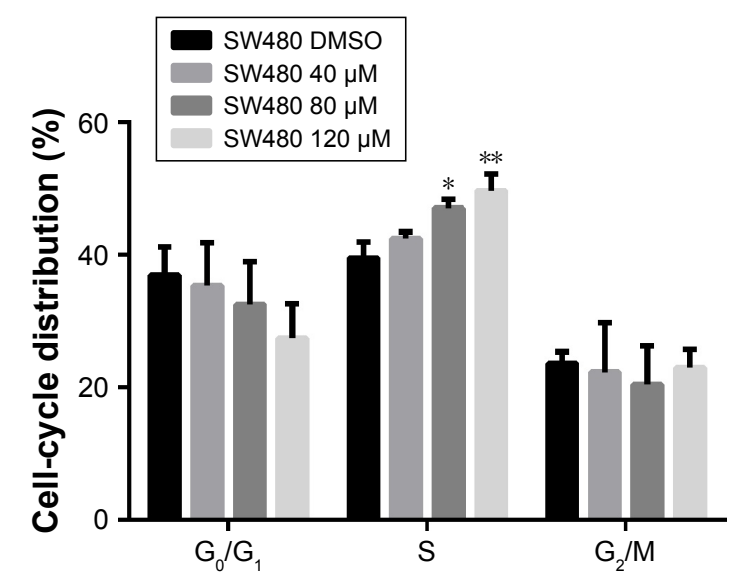

D

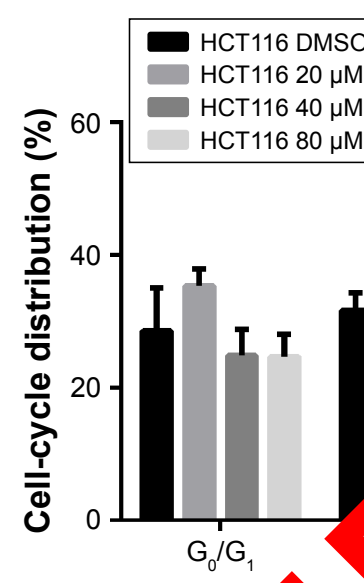

HCT116 cells

Figure 3 Effect of lupeol on cell-cycle analysis of SW480 and HCTII 6 cells assessed by flow cytometry.

Notes: Lupeol triggered cell-cycle arrest in the S phase in the two colorectal cancer cell lines. (A) SW480 cells we reated wit yarious 80 , and $120 \mu \mathrm{M}$ ) for 24 hours. Peaks represent the $\mathrm{G}_{0} / \mathrm{G}_{1}, \mathrm{~S}$, and $\mathrm{G}_{2} / \mathrm{M}$ phases in the cell cycle, respectively. (B) $\mathrm{HC} 6 \mathrm{cells}$ w for 24 hours. Percentages of cell numbers in the S phase of the cell cycle were significantly higher in (C) SW48 'rells . D CTII6 celle fter 24 hours' lupeol treatment. All data expressed as mean $\pm S D(n \geq 3)$. *P<0.05; ** $P<0.01$.

Abbreviation: DMSO, dimethyl sulfoxide.

the number of SW480 and HCT116 cells in the S phase of the cell cycle (Figure 3C and D). This suggested that lupeol significantly induced S-phase cell-cycle arrest of both CRC cell types.

\section{Effect of lupeol on cell migration in SW480 and HCTI 16 cells}

\section{Cell-migration assays were applied using the anSu} Both CRC cell types exhibited remarkab reduce higratio after lupeol treatment (Figure 4A an 3 ). 1 v" showernat 40 and $80 \mu \mathrm{M}$ lupeol almost abs tely block cell invasion for HCT116 and SW480 ce res, ctively. In m, lupeol significantly inhibited mi ation of SW and HCT116 cells in a dosage-depender nanner (Figure 40 nd D).

\section{Effect of lupeo trans iption activity in Wnt,$\rho-\mathrm{Ca}_{\mathrm{a}}$ enin att way}

We ne evaluat the effed of lupeol treatment on transcription lo in the Wnt $\beta$-catenin pathway for SW480 and HCT116 cell $\mathrm{s}$ s using quantitative reverse-transcription PCR. Lupeol treatment aused a significant decrease in the transcription level of CTNNB1 expression in HCT116 cells, while not causing significant change in SW480 cells. Lupeol treatment also inhibited $C M Y C$ - and $C C N D 1$-transcription activation in SW480 and HCT116 cells $(P<0.05)$. Interestingly, transcription levels of TCF4 and CLDN1 in HCT116 cells were decreased and CCNA2 mRNA in SW480 cells decreased to different degrees, also exhibiting significant differences compared to the control group ( $P<0.05$; Figure $5 \mathrm{~A}$ and $\mathrm{B})$.

\section{Effect of lupe on the protein levels in $\checkmark$ nt- $\beta$-catenin pathway}

Jext, we so ht to explore protein levels at which lupeol spressed $\int \mathrm{C}$ cell lines. We detected protein-expression levo catenin, TCF4, cMyc, cyclin D1, claudin 1, cyclin A2 in SW480 and HCT116 cells by Western blot analysis (Figure 6A-D). Results showed that lupeol decreased $\beta$-catenin and TCF4 mRNA expression in a dosagedependent manner (Figure 6E and F). In both lupeol-treated cell lines, protein-expression levels of cMyc and cyclin D1 decreased compared with the control group $(P<0.05$; Figure $6 \mathrm{E}$ and $\mathrm{F}$ ). Corresponding with mRNA expression, protein-expression levels of claudin 1 in HCT116 cells and cyclin A2 in SW480 cells upon lupeol treatment decreased compared with the control group ( $P<0.05$; Figure $6 \mathrm{E}$ and $\mathrm{F})$. This finding suggests that lupeol attenuated Wnt- $\beta$-catenin signaling activity and suppressed the expression of cMyc, cyclin D1, and cyclin A2, thus impeding proliferation and arresting the cell cycle in CRC cells.

\section{Effect of lupeol on protein expression in Wnt- $\beta$-catenin pathway}

Translocation of $\beta$-catenin to the nucleus is vital for transcription of downstream Wnt- $\beta$-catenin genes. We explored the localization of $\beta$-catenin, TCF4, cMyc, cyclin D1, claudin 1 , and cyclin A2 after lupeol treatment. In HCT116 cells, there was a decrease in $\beta$-catenin protein expression in lateral cell membranes after lupeol treatment (Figure 7B). However, no inhibited translocation of $\beta$-catenin to the nucleus was 
A

\section{SW480 cells}

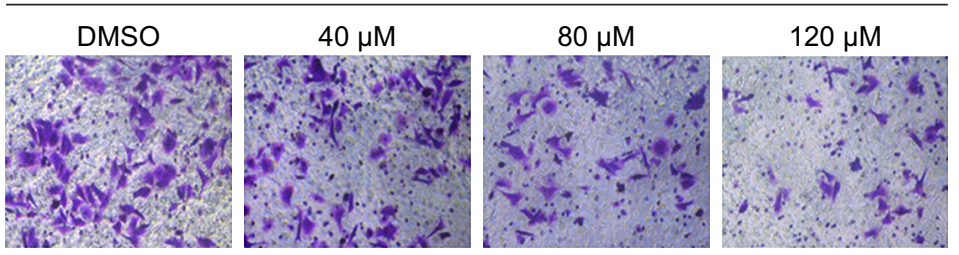

B

HCT116 cells

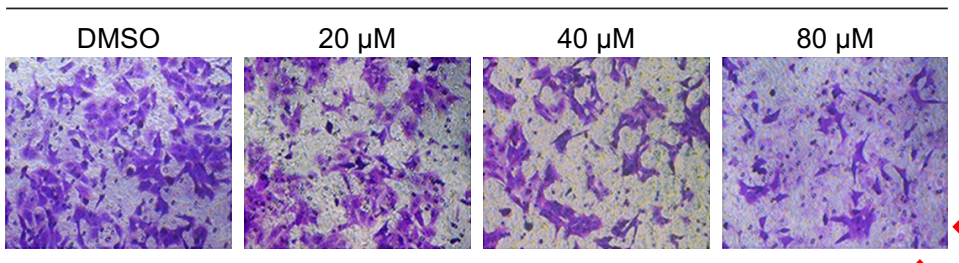

C

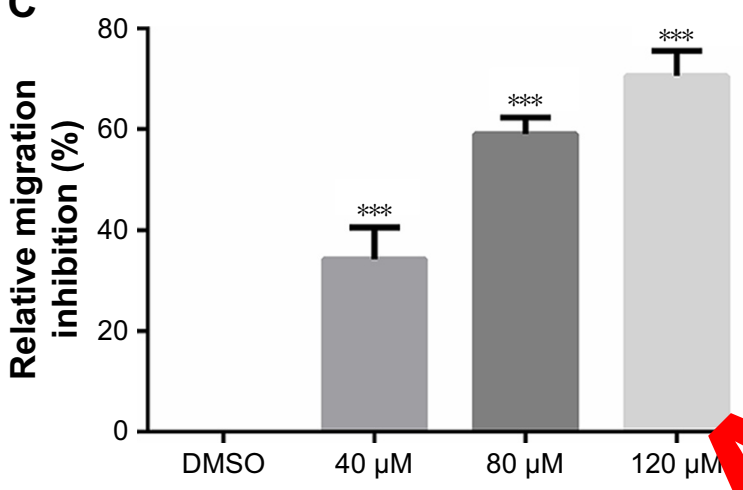

SW480 cells

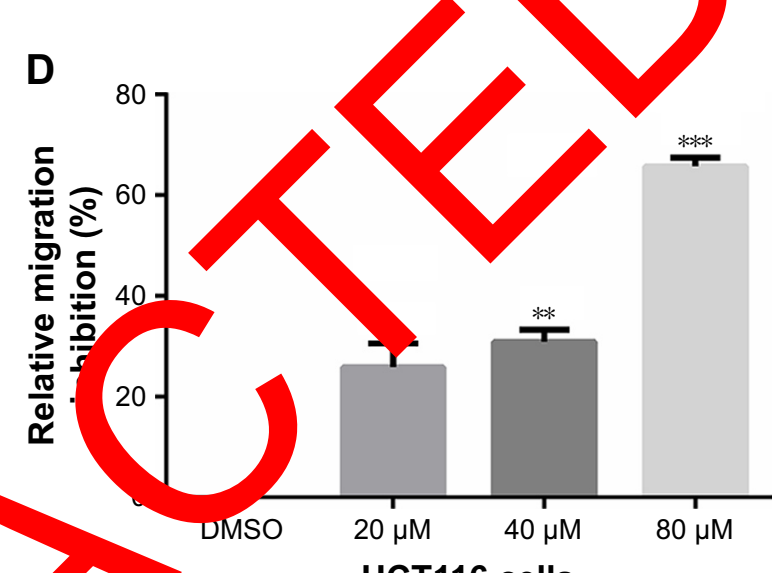

HCT116 cells

Figure 4 Effect of lupeol on cell migration of SW480 and HCTI cells a sed by t swell assay.

Notes: Lupeol suppressed cell migration in the two colorecta ncer cell l s. (A) SW 0 cells were treated with various concentrations of lupeol ( 0 , 40,80 , and I20 $\mu \mathrm{M}$ ) for 24 hours. (B) HCTII 6 cells were treated with lupeol (0, 40, and 8 , Mus 24 ho, is. Numbers of migrated (C) SW480 cells and (D) HCTII6 cells were significantly decreased after lupeol treatment for 24 hours. All data pres $* P<<0.05 ; * * P<0.01 ; * * * P<0.001$.

Abbreviation: DMSO, dimethyl sulfoxide.

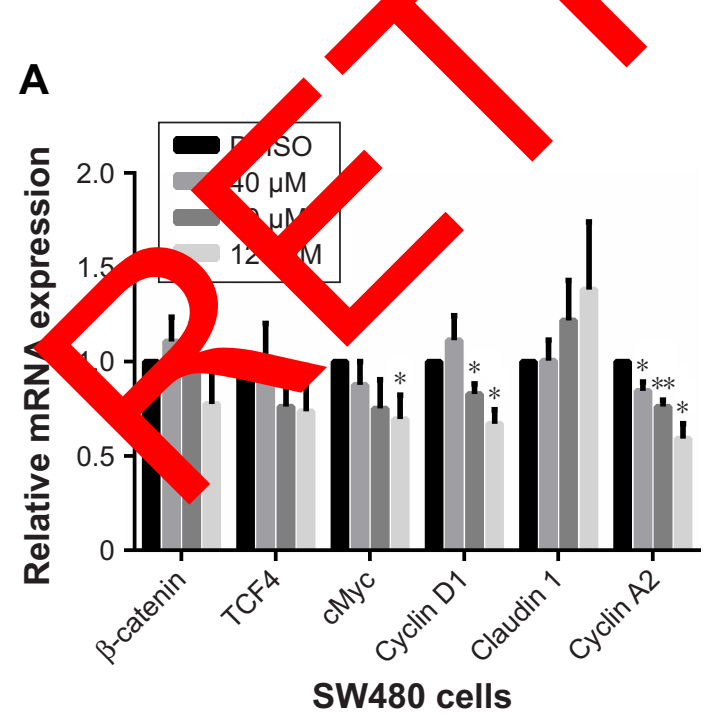

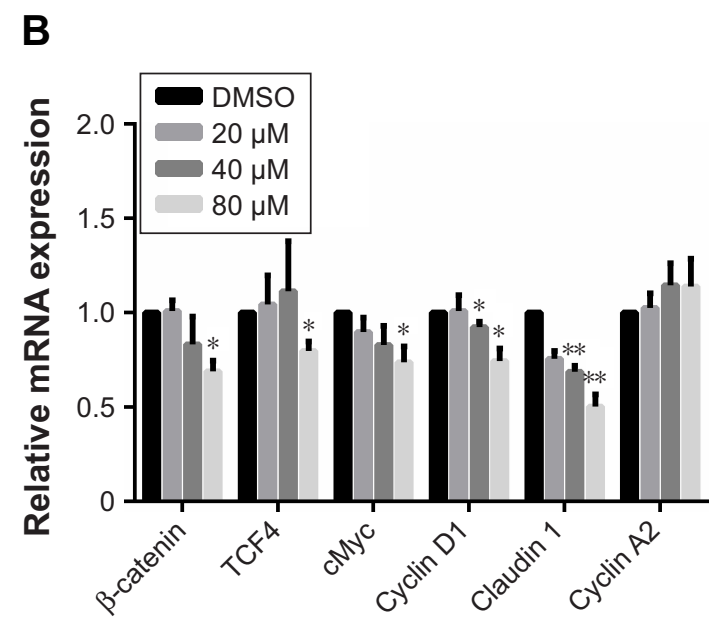

HCT116 cells

Figure 5 Effect of lupeol on transcription activity of the Wnt- $\beta$-catenin pathway of SW480 and HCTII6 cells.

Notes: Lupeol suppressed transcription activity of the Wnt- $\beta$-catenin pathway in the two colorectal cancer cell lines. (A) SW480 cells were treated with various concentrations of lupeol $(0,40,80$, and I $20 \mu \mathrm{M})$ for 24 hours. (B) HCTI I 6 cells were treated with lupeol $(0,20,40$, and $80 \mu \mathrm{M})$ for 24 hours. mRNA expression of the two cell lines was detected by reverse-transcription quantitative PCR analysis. All data expressed as mean $\pm S D(n \geq 3)$. $* P<0.05 ; * * P<0.01$.

Abbreviation: DMSO, dimethyl sulfoxide. 

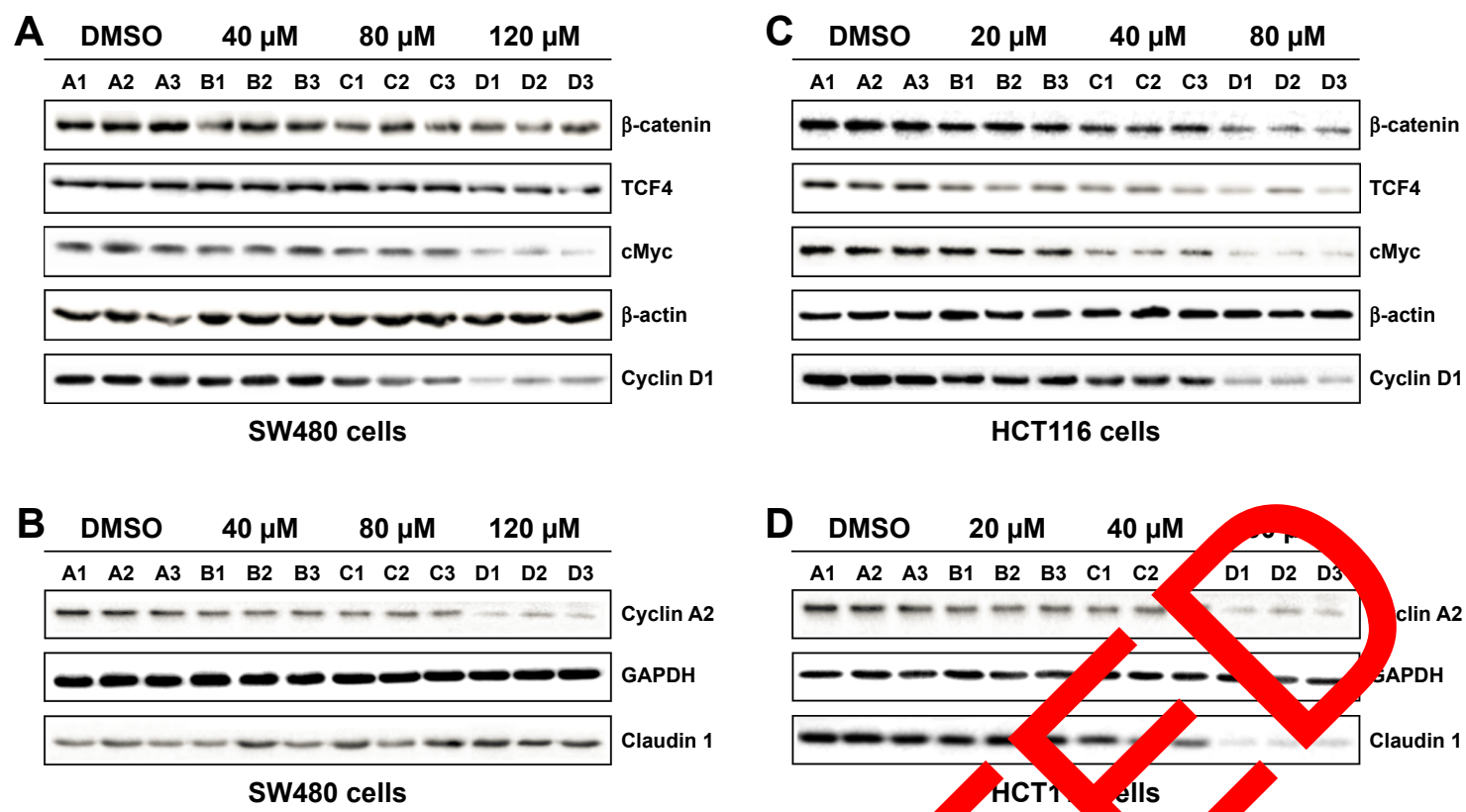

E

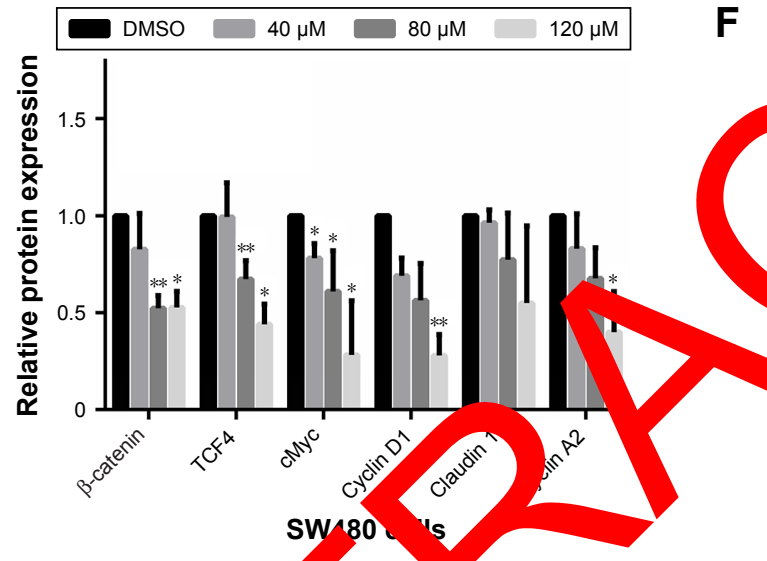

D DMSO $20 \mu \mathrm{M} \quad 40 \mu \mathrm{M}$

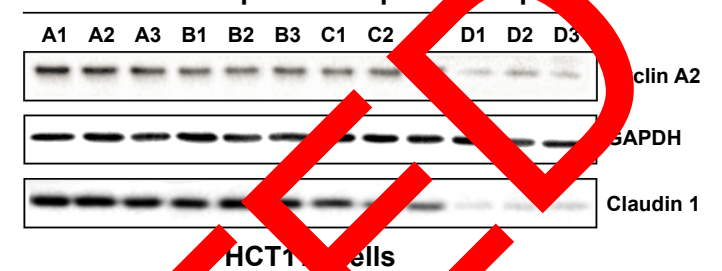

E

Figure 6 Effect of lupeol on the protein ley $\beta$-Catenin, TCF4, cMyc, cyc the 1 (B) claudin 1 cyclin A2 protein expression in SW480 cells with lupeol or DMSO treatment were determined by Western blot analysis. (C) $\beta$-Catenin, _F4, cM, yclin DI, and (ש) claudin I and cyclin A2 protein expression in HCTII6 cells with lupeol or DMSO treatment were determined by Western blot analy Graphs are $r \epsilon_{\text {, }}$ entative of three independent experiments showing the effect of lupeol on protein-expression levels in the Wnt- $\beta$ catenin pathway in (E) SW480 and (F) HCTII6 CG $* P<0.05 ; * * P<0.01 ; * * * P<0.001$. Abbreviation: DMSO, dim

observed in Sur480 co (Figure A). We further observed decreased uores nce it es of cMyc and cyclin D1 in nuc in bott $2 \mathrm{D}$ cell lines (Figure 7A, B, D, and E). Correspo, with Western blot analysis, fluorescence intensity of ch din 1 protein in HCT116 cells and cyclin A2 in SW480 cells was decreased upon lupeol treatment compared with control group (Figure 7C and F).

\section{Discussion}

Epidemiological evidence has shown an association between triterpenoid-enriched plant intake and decreased risk of developing CRC. ${ }^{13}$ Likewise, considerable evidence has shown that triterpenoids, such as lupeol, show an antitumor effect in certain cell lines. ${ }^{14,15}$ DNA damage is identified as a premise of cancer development, and lupeol has the potentiality to inhibit chemically induced DNA damage, both in vitro and in vivo. ${ }^{16}$ Recent studies have shown that in addition to chemoprevention, lupeol has a chemotherapeutic effect on prostate cancer, hepatic carcinoma, and gallbladder cancer. ${ }^{14,17-19}$ Lupeol can also regulate the immunoresponse and impart chemotherapeutic resistance. ${ }^{15,20}$ In a previous study, lupeol showed inhibition of melanoma cells with abnormally active Wnt- $\beta$-catenin signals by reducing Wnt signaling. ${ }^{21}$ Therefore, we wanted to evaluate the effect of lupeol treatment on different CRC cells with abnormally activated Wnt $-\beta$-catenin pathways. In the present study, we used two variants of CRC cell lines: SW480 cells (APC deleted, $\beta$-catenin wild type) and HCT116 cells (APC wild 


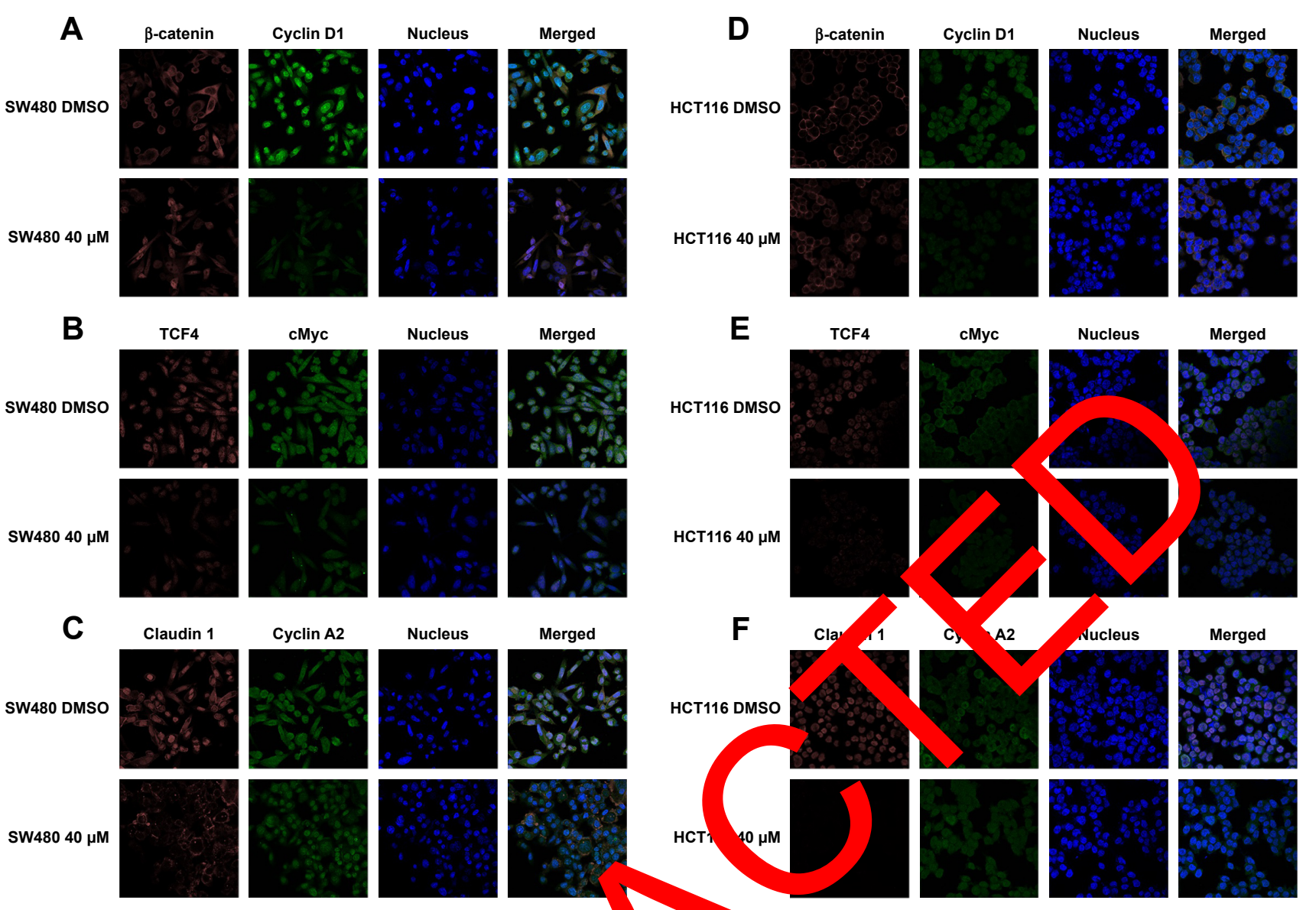

Figure 7 Effect of lupeol on protein expression in Wnt- $\beta$-catenin pathway of SW Notes: Immunofluorescence analysis showed the protein location to Wnt (E) TCF4, cMyc, and (F) claudin I and cyclin A2 protein loc ns in HC 6 cells m lupeol or DMSO treatment on photomicrography. Colorectal cancer cells were

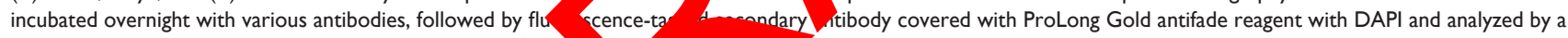
Nikon Ti fluorescence microscope.

Abbreviation: DMSO, dimethyl sulfoxide.

type, $\beta$-catenin mutated). Our resuls sho d that $20-\mathrm{r} 0 \mu \mathrm{M}$ lupeol treatment for $24 \mathrm{ho}$ is resulted in lecreased cell viability and increased ce arar apo tosis in a dose-dependent manner. These results in cord with earlier research

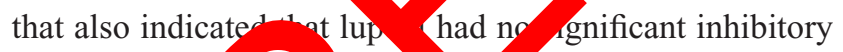
effect on CRC ells th did no por abnormal activation of Wnt- $\beta$ - enin 22 We further discovered that lupeol arrested cell cycle at the $\mathrm{S}$ phase and reduced the cell-migration cap lity of the two cell lines compared to the control groups. Molecdlar studies revealed that the anticancer effect of lupeol may in part be mediated by Wnt- $\beta$-catenin signaling-pathway suppression.

Constitutive Wnt- $\beta$-catenin pathway activation is characteristic of most CRC tumorigenesis. ${ }^{6}$ Wnt- $\beta$-catenin pathway plays a pivotal role in regulating homeostasis and self-renewal of tissue in which $\beta$-catenin is involved in regulation of cell adhesion and gene transcription. ${ }^{23-25}$ $\beta$-Catenin in the nucleus serves to activate TCF-dependent transcription, leading to increased expression of downstream genes, including $c M Y C, C C N D 1, C C N A 2$, and MMP7.7,9,26 Studies have shown that $\beta$-catenin also interacts with growth-factor receptors in signal-transduction patterns during tumorigenesis. ${ }^{27}$ Tarapore et al found that lupeol significantly reduced CTNNB1-transcription levels in DLD and HCT116 cells with abnormally activated Wnt- $\beta$-catenin signals assessed by TopFlash assay, which supports the inhibitory action of lupeol on Wnt- $\beta$-catenin signaling. ${ }^{22}$ In our study, lupeol treatment decreased expression of $\beta$-catenin and TCF 4 protein and decreased mRNA and protein expression of downstream $c M Y C$ and $C C N D 1$ in two CRC cell lines. The inhibitory effect of lupeol on highly metastatic HCT116 cells was stronger than that on SW480 cells, and the expression of $\beta$-catenin in HCT116 cells on lateral cell membranes associated with cell attachment was suppressed. ${ }^{28}$ In SW480 cells, inhibition of $\beta$-catenin translocation was not observed after lupeol treatment, which might have been due to subsequent 
ubiquitination and degradation of $\beta$-catenin, which could affect its positive control over transcription activity in the nucleus. ${ }^{29}$ Therefore, it is possible that the anticancer effect of lupeol in CRC cells is due to reduced nuclear expression of CTNNB1 and formation of $\beta$-catenin-TCF 4 complexes, with subsequent disruption of signal transduction in the Wnt- $\beta$-catenin pathway. Furthermore, lupeol treatment resulted in significant decreases in the viability and migration of SW480, HCT116, and DLD1 cells with APC or CTNNB1 mutations, with no effect on RKO cells carrying wild-type $A P C$ and $C T N N B 1 .{ }^{22}$ This indicates that the inhibitory effect of lupeol on cell proliferation is probably more sensitive to CRC cells with $A P C$ and CTNNB1 mutations.

Several $\beta$-catenin/TCF4 target genes like $c M Y C$ and $C C N D 1$ are supposed to accelerate metabolic activation of the cell cycle. cMyc interacts with prereplication to form a complex located in the early-DNA-synthesis site, which has a direct impact on DNA replication. Its overexpression bypasses the $\mathrm{G}_{1} / \mathrm{S}$ phase-division checkpoint, increasing DNA-replication activity and DNA damage. ${ }^{30}$ Cyclin D-CDK $4 / 6$ complexes block the transcription of genes, negatively controlling cell cycles like that of the $\mathrm{Rb}$ tumor suppressor protein and allow the cell to go through the $G_{1}$ checkpoint, thereby regulating cell-cycle progressi sustaining genomic integrity. ${ }^{31}$ Cyclin A2 is synthesiz the beginning of the $\mathrm{S}$ phase and binds to $\mathrm{CD}^{\mathrm{ra}}$ to pron DNA synthesis. ${ }^{32}$ In our study, lupeol sig nicant reduc cell viability, induced apoptosis, and $k$ eked th all cuclo in the $\mathrm{S}$ phase of the two $\mathrm{CRC}$ cell res. F. cimore, quantitative PCR and Western blot yses shom mRNA and protein expression of down, ream CND1 and $M Y C$ was reduced. CCNA2 was wnregulated SW480 cells, but not in HCT116 cely Similany, lupeol can arrest the cell cycle in the $S$ phas red ang the expression of $\beta$-catenin protein and $C A$ D 1 an $M Y$ tre cription in hepatoma and melanom cells. ${ }^{3}$ Sinco ynthesis of DNA, histones, and rel d enzy that lupeo ad reduce protein levels of $\beta$-catenin and TCF4 and reduce $\mathrm{m}$ VA and protein expression of downstream cycle genes like $M Y C$ and $C C N D 1$ in both cell lines and CCNA2 in SW480 cells so as to inhibit cell proliferation and arrest the cell cycle of CRC cells by repressing tetraploid formation and thus the mitosis process. ${ }^{26}$

Cancer-cell invasion and migration are essential for cancer metastasis, and the claudin family is closely related to these processes. In tumorigenesis, excessive TCF4 binds claudin 1 to certain sites to promote $C L D N 1$ transcription, ${ }^{35}$ which not only contributes to $\mathrm{EMT}^{36}$ but also increases the expression of matrix metalloproteinases, promotes extracellular matrix destruction and tumor infiltration, ${ }^{37}$ and increases myosin-actin contractility to promote cell invasion and migration without affecting cell proliferation. ${ }^{38,39}$ Our results showed that lupeol downregulated CLDN1 expression in HCT116 cells, corresponding to their reduced migration rate evaluated by transwell assay, suggesting decreased myosin-actin interaction-mediated cell motility. In addition, $\beta$-catenin-TCF4 downstream CCNA2 is a novel target in CRC..$^{40}$ Downregulation of CCNA2 displays increased cell invasiveness by actin-filament re stributs through regulation of the Rho family, such as activation on $H O A$, leads to a decrease in cell adhesig and $\mathrm{p}$ otes $\mathrm{EV}$ processes. ${ }^{41,42}$ Cyclin A-CDK2 res ates APC mi ic pindle anchoring by phosphorylatio, $A^{D}$, which restrains microtubule attachment in attosis. hile ly ol significantly inhibited migratio or W480 celh owever, CCNA2 instead of $C L D N 1$ was don egulated. Although the results were not a crpared from our vious study on migration of SW480 ells, downr vulation of $C C N A 2$ did exist. Since CCNA2 gulates $\mathrm{my}$ progress in the genesis and development of 2C. liv cell migration and the cell cycle, the increase decrease in its expression in cancer cells cannot fully expran the invasion and migration of cells..$^{27,42,44}$ Therefore, the specific mechanism needs to be studied further.

\section{Conclusion}

We have provided evidences of anti-CRC effect of lupeol in cell viability, apoptosis, migration, cell-cycle arrest, and inactivation of Wnt- $\beta$-catenin signaling activity with the intervention of $\beta$-catenin nuclear translocation. The in vivo anticancer effect of lupeol is still not completely understood. Further research will be needed to elucidate the complicated mechanism of lupeol-induced Wnt- $\beta$-catenin inactivation, such as the knockdown assay. In addition, as lupeol is a pentacyclic triterpenoid belonging to over 30 triterpenoids that should also be explored, our research can provide evidence of the importance of dietary triterpenoids and interaction of lupeol with frequently mutated genes in initiative carcinogenesis pathways of CRC.

\section{Data sharing statement}

The data sets used and/or analyzed during the current study are available from the corresponding author on reasonable request. 


\section{Acknowledgments}

The authors would like to thank Dr Magid Nisar from Pakistan for editing the English text of a draft of this manuscript. In addition, YHW especially wishes to thank Professor Suhao Lin for his continuous guidance and support to her. This study was presented as an abstract at the Zhejiang Medical Genetics Annual Conference (2018, Hangzhou, People's Republic of China) and supported by grants from the Zhejiang Provincial Natural Science Foundation of China (LY13H250002).

\section{Author contributions}

YHW, LJJ, ZFL, and DH conceived and designed the study. YHW, DH, YQQ, and XHY drafted the manuscript. YHW, DH, YQQ, XZT, and KKW participated in implementation of the study. XHY, SJS, and XLK assisted in collecting the data. DH, YQQ, and KKW performed the statistical analysis. All authors contributed to data analysis, drafting and revising the article, gave final approval of the version to be published, and agree to be accountable for all aspects of the work.

\section{Disclosure}

The authors report no conflicts of interest in this work.
13. Mcdougall GJ, Allwood JW, Pereira-Caro G, et al. Novel colonavailable triterpenoids identified in raspberry fruits exhibit antigenotoxic activities in vitro. Mol Nutr Food Res. 2017;61(2):1600327.

14. Prasad S, Nigam N, Kalra N, Shukla Y. Regulation of signaling pathways involved in lupeol induced inhibition of proliferation and induction of apoptosis in human prostate cancer cells. Mol Carcinog. 2008;47(12): 916-924.

15. Zhu Y, Li X, Chen J, et al. The pentacyclic triterpene lupeol switches M1 macrophages to M2 and ameliorates experimental inflammatory bowel disease. Int Immunopharmacol. 2016;30:74-84.

16. Srivastava AK, Mishra S, Ali W, Shukla Y. Protective effects of lupeol against mancozeb-induced genotoxicity in cultured human lymphocytes. Phytomedicine. 2016;23(7):714-724.

17. Saleem M, Murtaza I, Witkowsky O, Kohl AM, Maddodi N. Lupeol triterpene, a novel diet-based microtubule tang agent: disrupts survivin/cFLIP activation in prostate ca cells. chem Biophys Res Commun. 2009;388(3):576-582.

18. Liu F, He Y, Liang Y, et al. PI3-k inhibition s ergistically promoted the anti-tumor effect cupeor hepatocellu carcinoma. Cancer Cell Int. 2013;13(1) -114

19. Liu Y, Bi T, Shen G, Lupeo duces a sis and inhibits invasion in gallbladde cinon GBC-SD cerls by suppression of EGFR/MMP-9 ghalin way. Cyt chnology. 2016;68(1): 123-133.

20. Liu Y, Bi T W, et al. Lup nances inhibitory effect of 5-fluorouran on ha n gastric carunoma cells. Naunyn Schmiedebergs Arch Pharmacon. 16;389(5):477-484.

21. Ta S, Siddiqui IA, leem M, Adhami VM, Spiegelman VS, aktar $\mathrm{H}$. Specific targeting of $\mathrm{Wnt} / \beta$-catenin signaling in human elanoma cells a dietary triterpene lupeol. Carcinogenesis. 2010; (10):1844-18

22. Ta ore RS, Si qui IA, Adhami VM, Spiegelman VS, Mukhtar H. The one lupeol targets colorectal cancer cells with constituvely active Wnt/B-catenin signaling. Mol Nutr Food Res. 2013;57(11): \%o 58 .

Yan M, Li G, An J. Discovery of small molecule inhibitors of the Wnt $/ \beta$ catenin signaling pathway by targeting $\beta$-catenin/Tcf4 interactions. Exp Biol Med. 2017;242(11):1185-1197.

Sebio A, Kahn M, Lenz HJ. The potential of targeting Wnt/ $\beta$-catenin in colon cancer. Expert Opin Ther Targets. 2014;18(6):611-615.

25 . Deitrick J, Pruitt WM. Wnt $/ \beta$ catenin-mediated signaling commonly altered in colorectal cancer. Prog Mol Biol Transl Sci. 2016;144: 49-68.

26. Kolligs FT, Bommer G, Göke B. Wnt/beta-catenin/tcf signaling: a critical pathway in gastrointestinal tumorigenesis. Digestion. 2002;66(3): 131-144.

27. Saleem M, Murtaza I, Tarapore RS, et al. Lupeol inhibits proliferation of human prostate cancer cells by targeting beta-catenin signaling. Carcinogenesis. 2009;30(5):808-817.

28. Kaler P, Augenlicht L, Klampfer L. Activating mutations in $\beta$-catenin in colon cancer cells alter their interaction with macrophages; the role of snail. PLoS One. 2012;7(9):e45462.

29. Shang $\mathrm{S}, \mathrm{Hua} F, \mathrm{Hu} Z \mathrm{ZW}$. The regulation of $\beta$-catenin activity and function in cancer: therapeutic opportunities. Oncotarget. 2017;8(20):33972-33989.

30. Dorasamy MS, Choudhary B, Nellore K, Subramanya H, Wong PF. Dihydroorotate dehydrogenase inhibitors target c-Myc and arrest melanoma, myeloma and lymphoma cells at S-phase. J Cancer. 2017; 8(15):3086-3098.

31. Dozier C, Mazzolini L, Cénac C, et al. CyclinD-CDK4/6 complexes phosphorylate CDC25A and regulate its stability. Oncogene. 2017; 36(26):3781-3788.

32. Yan J, Hao C, Delucia M, et al. CyclinA2-cyclin-dependent kinase regulates SAMHD1 protein phosphohydrolase domain. J Biol Chem. 2015;290(21):13279-13292.

33. Saleem M, Maddodi N, Abu Zaid M, et al. Lupeol inhibits growth of highly aggressive human metastatic melanoma cells in vitro and in vivo by inducing apoptosis. Clin Cancer Res. 2008;14(7):2119-2127. 
34. He Y, Liu F, Zhang L, et al. Growth inhibition and apoptosis induced by lupeol, a dietary triterpene, in human hepatocellular carcinoma cells. Biol Pharm Bull. 2011;34(4):517-522.

35. Ouban A. Claudin-1 role in colon cancer: an update and a review. Histol Histopathol. 2018;33(10):1013-1019.

36. Zhao X, Zou Y, Gu Q, et al. Lentiviral vector mediated claudin1 silencing inhibits epithelial to mesenchymal transition in breast cancer cells. Viruses. 2015;7(6):2965-2979.

37. Smith JJ, Deane NG, Dhawan P, Beauchamp RD. Regulation of metastasis in colorectal adenocarcinoma: a collision between development and tumor biology. Surgery. 2008;144(3):353-366.

38. van Itallie CM, Tietgens AJ, Anderson JM. Visualizing the dynamic coupling of claudin strands to the actin cytoskeleton through ZO-1. Mol Biol Cell. 2017;28(4):524-534.

39. Smith JJ, Deane NG, Dhawan P, Beauchamp RD. Regulation of metastasis in colorectal adenocarcinoma: a collision between development and tumor biology. Surgery. 2008;144(3):353-366.
40. Yang F, Hu Y, Liu HX, Wan YJ. MiR-22-silenced cyclin A expression in colon and liver cancer cells is regulated by bile acid receptor. $J$ Biol Chem. 2015;290(10):6507-6515.

41. Arsic N, Bendris N, Peter M, et al. A novel function for cyclin A2: control of cell invasion via RhoA signaling. J Cell Biol. 2012;196(1): $147-162$.

42. Cheung CT, Bendris N, Paul C, et al. Cyclin A2 modulates EMT via $\beta$-catenin and phospholipase C pathways. Carcinogenesis. 2015;36(8): 914-924.

43. Beamish H, de Boer L, Giles N, Stevens F, Oakes V, Gabrielli B. Cyclin $\mathrm{A} / \mathrm{cdk} 2$ regulates adenomatous polyposis coli-dependent mitotic spindle anchoring. J Biol Chem. 2009;284(42):29015-29023.

44. Yasmeen A, Berdel WE, Serve H, Müller-Tidow C. E- and A-type cyclins as markers for cancer diagnosis and prognosis. Expert Rev Mol Diagn. 2003;3(5):617-633.

Video abstract

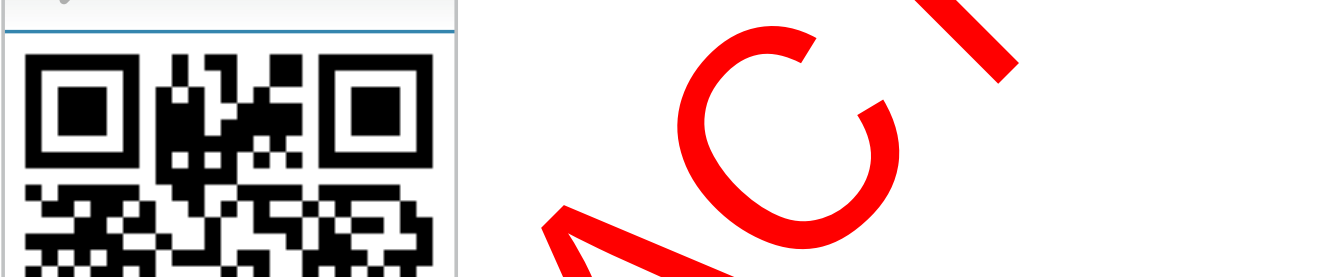

OncoTargets and Therapy

Dovepress

\section{Publish your work in this journal}

OncoTargets and Therapy is an international, peer-reviewed, open access journal focusing on the pathological basis of all cancers, potential targets for therapy and treatment protocols employed to improve the management of cancer patients. The journal also focuses on the impact of management programs and new therapeutic agents and protocols on patient perspectives such as quality of life, adherence and satisfaction. The manuscript management system is completely online and includes a very quick and fair peer-review system, which is all easy to use. Visit http://www.dovepress.com/testimonials.php to read real quotes from published authors. 